\title{
Relationship between platelet aggregatory and heparin-induced thrombocytopenia type II
}

\author{
Harunobu Iwase ${ }^{1}$, Hiroko Kariyazono ${ }^{2}$, Junko Arima ${ }^{3}$, Hiroyuki Yamamoto ${ }^{4}$, \\ Kazuo Nakamura ${ }^{1, *}$ \\ ${ }^{1}$ Department of Biopharmaceutics, Nihon Pharmaceutical University, Saitama, Japan \\ ${ }^{2}$ Department of Pharmacy, Nagasaki International University, Nagasaki, Japan \\ ${ }^{3}$ Department of Clinical Pharmacy and Pharmacology, Graduate School of Medical and Dental Sciences, Kagoshima University, \\ Kagoshima, Japan \\ ${ }^{4}$ Department of Cardiovascular and Gastroenterological Surgery, Advanced Therapeutics Cardiovascular and Respiratory Disorder, \\ Graduate School of Medical and Dental Sciences, Kagoshima University, Kagoshima, Japan
}

\section{Email address:}

iwase@nichiyaku.ac.jp (H. Iwase), karihiro@niu.ac.jp (H. Kariyazono), arimaj@m3.kufm.kagoshima-u.ac.jp (J. Arima), h-yamamoto@h5.dion.ne.jp (H. Yamamoto), kazunaka@nichiyaku.ac.jp (K. Nakamura)

\section{To cite this article:}

Harunobu Iwase, Hiroko Kariyazono, Junko Arima, Hiroyuki Yamamoto, Kazuo Nakamura. Relationship between Platelet Aggregatory and Heparin-Induced Thrombocytopenia Type II. Science Research. Vol. 2, No. 4, 2014, pp. 78-86. doi: 10.11648/j.sr.20140204.13

\begin{abstract}
Heparin-induced thrombocytopenia type II (HIT) is a significant adverse effect of heparin treatment in either therapeutic or prophylactic doses. HIT is an immune-mediated disorder caused by IgG antibodies that bind to platelet factor 4 (PF4), which becomes an antigenic target when bound to heparin. The possibility of HIT is suspected when patients show a reduction in the platelet count while receiving heparin. However, the diagnosis of HIT may be difficult on the basis of clinical symptoms alone, especially in patients with other diseases that may induce thrombocytopenia. Therefore, confirmation of HIT by using biologic or antigen assays is required. To analyze whether two patients in whom thrombocytopenia was induced after initiating administration of unfractionated heparin during percutaneous transluminal coronary angioplasty or coronary artery bypass grafting surgery had HIT, we measured levels of platelet aggregability, anti-heparin-PF4 complex antibody (anti-HIT antibody), tumor necrosis factor (TNF)-alpha, TNF-receptor 1 (TNF-R1), interleukin (IL)-6, and thrombin-antithrombin III complex (TAT). The two patients were judged to be HIT-positive from the results that platelet aggregation induced with induced by ADP $1 \mu \mathrm{M}$ as well as collagen $0.2 \mu \mathrm{g} / \mathrm{mL}$ increased after addition of UFH. ELISA results of two patients showing optical density (OD) values greater than 0.40 were regarded as positive. Additionally, the levels of TNF-alpha and TAT in both patients were higher than in the control patients who underwent CABG without thrombocytopenia after heparin therapy initiation. The results suggest that blood coagulation is enhanced and an inflammatory reaction is induced in the endothelial cells of patients with HIT. In conclusion, the combined measurement of platelet aggregation and anti-HIT antibodies is crucial for defining HIT status, and measurement of TNF-alpha and TAT may play a significant role in the practice of anticoagulant therapy.
\end{abstract}

Keywords: HIT, Unfractionated Heparin, Platelet Aggregability, Anti-HIT Antibodies, TNF-alpha, TAT

\section{Introduction}

Heparin is an effective anticoagulant for the prevention of venous thromboembolism and treatment of venous thrombosis and pulmonary embolism [1-3]. It is often used in the treatment of unstable angina, acute myocardial infarction and peripheral arterial disease, as well as after mechanical heart valve replacement [4-6]. However, administration of heparin frequently induces a reduction in platelet count. This event, which is called heparin-induced thrombocytopenia, can be classified as either type I or type II. Heparin-induced thrombocytopenia type I affects up to $10 \%$ of patients under treatment with heparin [3,7]. On the other hand, heparin-induced thrombocytopenia type II (HIT) is an immune-mediated disorder [8,9] and a life-threatening and limb-threatening prothrombotic complication $[3,10]$. HIT is characterized by a significant reduction in platelets (more than 30\%) -generally after the fifth day of therapy-, 
which usually resolves within 5 to 15 days after therapy has been suspended. However, in some cases, the recovery may take months [11-13]. Patients with HIT not only require withdrawal of any heparin but they absolutely need an alternative anticoagulation to avoid thrombotic events [14]. Previous reports showed that up to $8 \%$ of heparinized patients tend to produce antibodies associated with heparin-induced thrombocytopenia [10] and that approximately $1 \%$ to $5 \%$ of patients on heparin treatment develop HIT $[15,16]$. It is widely accepted that HIT is caused by immunoglobulin (Ig) $\mathrm{G}$ antibodies that recognize complexes of heparin (or certain other polyanions) and platelet factor 4 (PF4). Anti-PF4/heparin complex antibodies (anti-HIT antibodies) have been detected in the plasma of HIT patients [17-19]. Anti-HIT antibodies cause platelet activation, which in turn induces the release of prothrombotic microparticles, platelet consumption, and thrombocytopenia [20-22]. Furthermore, anti-HIT antibodies activate monocytes and endothelial cells, resulting in accelerated generation of thrombin [23-25] and causing thrombotic complications. The incidence of HIT varies with several factors such as heparin type, patient type, and sex [26-28]. Francis and colleagues [29] reported that anti-HIT antibody formation was significantly lower in cardiac surgery patients who received porcine unfractionated heparin (UFH) than in those who received bovine UFH. In addition, patients given bovine UFH had higher anti-HIT antibody levels than those treated with porcine UFH or low-molecular-weight heparin [26,30]. The diagnosis of HIT is based on clinical criteria, such as thrombocytopenia and thrombosis, and laboratory data, such as platelet count dynamics and the detection of anti-HIT antibodies [3]. To confirm a positive diagnosis, a number of criteria must be fulfilled; these include anti-HIT antibodies seroconversion, as well as thrombocytopenia or other clinical manifestations such as skin lesions at heparin injection sites or acute systemic reactions after intravenous bolus administration $[22,27,30]$. A mnemonic device, the " 4 Ts" of HIT, has been developed to remember the salient clinical features of HIT, thus facilitating patient assessment and HIT diagnosis [31]: the degree of Thrombocytopenia, the Timing of the platelet fall, the presence of Thrombosis or other sequelae, and other potential causes of thrombocytopenia [32-34]. Despite the utility of this memory device, severe morbidity and mortality in HIT patients persists because of lack of awareness accompanied by a delayed diagnosis [35].

In the present study, we aimed to confirm the presence of HIT in 2 patients who had been suspected of having HIT because of a striking decrease in platelet counts after UFH [i.e., heparin sodium] administration as an anticoagulant therapy during percutaneous transluminal coronary angioplasty (PTCA) or coronary artery bypass grafting (CABG) surgery and recovery to the normal range after cessation of UFH. This was achieved by measuring levels of platelet aggregability, anti-HIT antibodies, tumor necrosis factor (TNF)-alpha, TNF-receptor 1 (TNF-R1), and thrombin-antithrombin III complex (TAT).

\section{Materials and Methods}

\subsection{Reagents}

ADP (Boehringer Mannheim, Mannheim, Germany) and collagen (General Reagent Horse Tendon Collagen, Hormon-Chemie, Munich, Germany) were prepared as described in our previous report [36]. UHF was purchased from Fuso Pharmaceutical Industries (Osaka, Japan). All reagents are indicated as final concentrations.

\subsection{Study Design}

The study included 2 patients suspected of HIT; patient A (56-year-old man) had received PTCA, and patient B (67-year-old man) had undergone CABG surgery. A diagnosis of HIT based on clinical criteria such as decrease in platelet count by $50 \%$ or more or to less than $100 \times 10^{9} / \mathrm{L}$, new thromboembolic complication during UFH administration, or both conditions, and based on laboratory confirmed anti-HIT antibodies. The heparin-induced platelet activation test was used to detect anti-HIT antibodies. Platelet counts of patients A and B before starting heparin therapy were $180 \times 10^{9}$ and $200 \times 10^{9}$ cells/L, respectively. On the other hand, values of patient controls were $250 \times 10^{9}$ cells/L. Exclusion criteria were age younger than 18 years, no ongoing thrombosis, more than 21 days between onset of clinical symptoms and laboratory confirmation of HIT, cardiopulmonary bypass, and start of therapy more than 60 days after laboratory confirmation of HIT. Patients did not receive a blood transfusion and antibody preparations before and after an operation. Patient A was treated with aspirin (100 mg/day), pravastatin sodium (10 mg/day), and pindolol (5 mg/day) at the time of hospitalization. He had a history of heparin exposure in coronary angiography one month before. The electrocardiogram showed ST-segment depression in the left precordial leads. Laboratory tests showed normal levels of troponin and myoglobin. Unstable angina was diagnosed. Intravenous nitroglycerine and UFH were added to the patient's medication. His blood examination on admission was normal. However, a repeat test 12 hours after admission showed platelet $3 \times 10^{9}$ cells/L and HIT was suspected. Patient B was treated with clopidogrel sulfate (75 $\mathrm{mg}$ /day), aspirin (100 mg/day), atorvastatin calcium hydrate (10 mg/day), amlodipine besilate $(2.5 \mathrm{mg} /$ day $)$, and atenolol $(50 \mathrm{mg} /$ day) at the time of hospitalization. He received CABG surgery because of angina. On POD-1, diffuse coronary thrombosis was shown. Percutaneous coronary intervention was performed for native vessels under UFH administration and thrombolysis in myocardial infarction was established. After surgery, the platelet count showed platelet $12 \times 10^{9}$ cells/L, and HIT was suspected. Therefore, the use of heparin was stopped and argatroban was started as an alternative anticoagulation on postoperative day (POD)-2. His postoperative characteristics were follows; number of grafts was 3, operation time was $352 \mathrm{~min}$, operation blood 
loss was $1,051 \mathrm{ml}$. Blood collection in patients A and B was performed within 2 days after the occurrence of thrombocytopenia. Patients without thrombocytopenia by heparin therapy after CABG surgery served as patient controls $(n=17)$. Healthy volunteers served as the normal controls $(n=5)$. This study was approved by the local ethics committee, and informed written consent was obtained from each patient. Samples from the patient controls were obtained on postoperative day 14, and those from normal controls were collected before every meal. We measured three times of same specimens to confirm reproducibility of the methods.

\subsection{Platelet Preparation and Measurement of Platelet Aggregation}

Human blood was collected in $3.8 \%$ sodium citrate $(1 \mathrm{~mL}$ of anticoagulant per $9 \mathrm{~mL}$ of blood). Platelet-rich plasma (PRP) and platelet-poor plasma were prepared as previously reported [36-38]. Duplicate platelet counts were performed with a Coulter counter (Beckman Coulter, Inc., CA, USA). The platelet counts in all the PRP samples were adjusted to 2 $\times 10^{11}$ to $3 \times 10^{11}$ cells $/ \mathrm{L}$. Platelet aggregation was assessed with a Hematracer 801 (LMS Co., Ltd., Tokyo, Japan) following the turbidimetric method of Born and then quantified by light transmission as previously described [36-38].

\subsubsection{PRP Aggregation of Patients $A$ and $B$ in Response to Agonists After Addition of $\mathrm{UFH}$}

PRP samples incubated with a final concentration UFH of $0.2 \mathrm{IU} / \mathrm{mL}$ at room temperature for $10 \mathrm{~min}$ [39] served as the PRP aggregation samples of patients A and B. In contrast, PRP samples incubated without UFH served as the PRP aggregation control samples of patients A and B. PRP samples of the patient controls incubated with UFH served as the control PRP aggregation samples of patient controls. PRP samples of the patient controls incubated without UFH served as the control PRP aggregation control samples of patient controls. The platelet aggregation activity of these samples in response to ADP $1 \mu \mathrm{M}$ or collagen $0.2 \mu \mathrm{g} / \mathrm{ml}$ was evaluated by the percentage $(\%)$ of maximum aggregation (MA).

\subsubsection{Detection of anti-HIT Antibodies Using Platelet Aggregability}

Detection samples to detect anti-HIT antibodies were prepared by adding the respective plasma obtained from patients $\mathrm{A}$ and $\mathrm{B}$ to the $\mathrm{PRP}$ of the healthy volunteers at a ratio of $1: 1$ (volume ratio), adding UFH $(0.2 \mathrm{IU} / \mathrm{mL})$ to these samples, and then incubating the mixtures at room temperature for $10 \mathrm{~min}$. These samples served as the detection samples of patients A and B. Samples prepared in the same way but incubated without UFH served as the detection control samples of patients A and B. Platelet aggregability was evaluated as described earlier [36-38]. Anti-HIT antibodies detected by platelet aggregation test in accordance with procedure of HIT information center in Japan [40].

\subsubsection{Detection of anti-HIT Antibodies by Using ELISA}

Anti-HIT antibodies were measured with a commercial enzyme-linked immunosorbent assay (ELISA) kit (GTI Corp., Waukesha, WI, NJ, USA). The tests were performed in parallel according to the manufacturer's instructions for the GTI PF4 Enhanced ELISA test system, where test results showing optical density (OD) values greater than 0.40 are regarded as positive. A confirmatory step was performed on all positive ELISA results per manufacture guidelines, with a positive confirmatory result defined as $>50 \%$ decrease in absorbance in the presence of added heparin [41].

\subsubsection{Determination of Circulating Levels for TNF-Alpha, TNF-R1, and TAT}

The circulating plasma levels of TNF-alpha, TNF-R1, and TAT in the patients were measured using commercially available ELISA kits (TNF- $\alpha$ and TNF-R1; R\&D Systems, Inc., Minneapolis, MN, USA, TAT; Enzygnost, Dade Behring Marburg GmbH, Marburg, Germany).

\section{Results}

\subsection{Platelet Count}

Mean platelet counts of patients A and B before starting heparin therapy were $180 \times 10^{9}$ and $200 \times 10^{9}$ cells $/ \mathrm{L}$, respectively. After initiation of heparin therapy, mean platelet counts of patients A and B were $3 \times 10^{9}$ and $12 \times$ $10^{9}$ cells $/ \mathrm{L}$, respectively. On the other hand, values of patient controls were $250 \times 10^{9}$ cells $/ \mathrm{L}$.

\subsection{Changes in Platelet Aggregation in Patients $A$ and $B$ Adding UFH (0.2 IU/mL)}

As shown in Fig.1. (1), when UFH-treated PRPs (PRP aggregation samples) of patients $\mathrm{A}$ and $\mathrm{B}$ were stimulated with ADP $1 \mu \mathrm{M}$, secondary aggregation was induced, and MAs (\%) of these PRP were high values (A: patient A; 78\%, B: patient B; 66\%). On the other hand, when UFH-untreated PRP (PRP aggregation control samples) of patients A and B were stimulated with ADP $1 \mu \mathrm{M}$, primary aggregation was induced, and MAs (\%) of PRP were low values (C: patient A; 28\%, D: patient B; 7\%). As shown in Fig.1. (2), when the PRP aggregation samples of patients $A$ and $B$ were stimulated with collagen $0.2 \mu \mathrm{g} / \mathrm{mL}$, strong aggregation was induced, and MAs (\%) were high values (A: patient A; 84\%, $\mathrm{B}$ : patient $\mathrm{B} ; 54 \%)$. On the other hand, when the PRP aggregation control samples of patients $\mathrm{A}$ and $\mathrm{B}$ were stimulated with collagen $0.2 \mu \mathrm{g} / \mathrm{mL}$, each MA (\%) was an extremely low value (C: patient A; 4\%, D: patient B; 2\%). As shown in Fig.1. (3), when the detection samples of patient A and B were stimulated with collagen $0.2 \mu \mathrm{g} / \mathrm{mL}$, strong aggregation was induced, and MAs (\%) of these samples were high values (A: patient $\mathrm{A} ; 81 \%$, B: patient $\mathrm{B}$; 


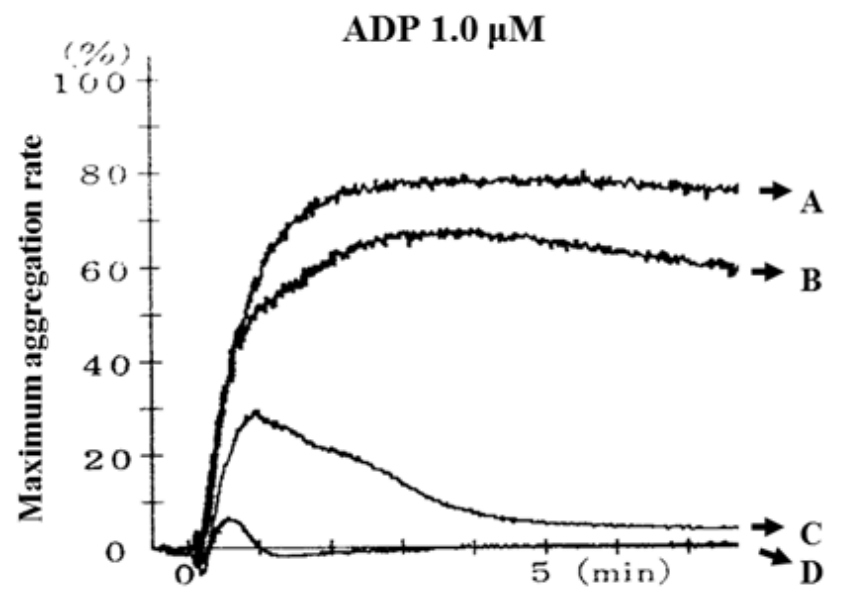

(1)

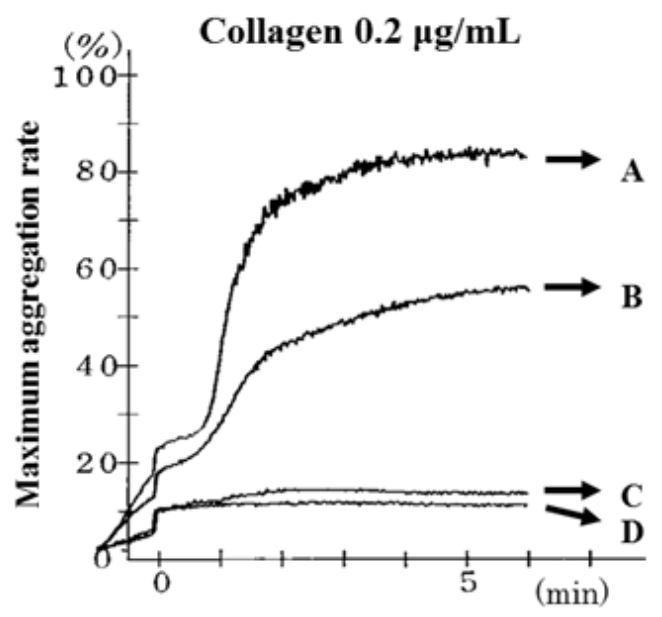

(2)

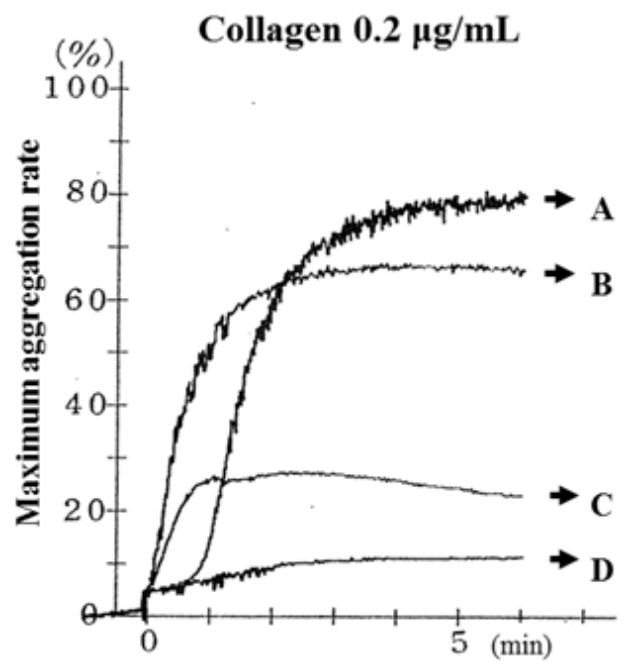

(3)

Figure 1. (1); PRPs were stimulated with ADP $1 \mu M$. In patient A's PRP incubated with UFH (PRP aggregation sample) (A). In patient $B$ 's $P R P$ incubated with UFH (PRP aggregation sample) (B). In patient $A$ 's PRP incubated without UFH (PRP aggregation control sample) (C). In patient $B$ 's $P R P$ incubated without UFH (PRP aggregation control sample) (D). (2); PRPs were stimulated with collagen $0.2 \mu \mathrm{g} / \mathrm{mL}$. In patient $A$ 's PRP incubated with UFH (PRP aggregation sample) (A). In patient $B$ 's PRP incubated with UFH (PRP aggregation sample) (B). In patient A's PRP incubated without UFH (PRP aggregation control sample) (C). In patient B's PRP incubated without UFH (PRP aggregation control sample) (D). (3); Anti-HIT antibodies was detected by turbidimetric method. Collagen $0.2 \mu \mathrm{g} / \mathrm{mL}$ was used as agonist. Detection samples were prepared by adding the respective plasma obtained from patients $A$ and $B$ to the PRP of the healthy volunteers at a ratio of 1:1 (volume ratio). In patient $A$ 's PRP incubated with UFH (detection sample) (A). In patient B's PRP incubated with UFH (detection sample) (B). In patient A's PRP incubated without UFH (detection control sample) (C). In patient $B$ 's PRP incubated without UFH (detection control sample) (D).

$68 \%$ ). On the other hand, when the corresponding detection control samples of patients $\mathrm{A}$ and $\mathrm{B}$ were stimulated with collagen $0.2 \mu \mathrm{g} / \mathrm{mL}$, each MA (\%) was an low value (C: patient A; $27 \%$, D: patient B; $16 \%$ ).

\subsection{OD Values of anti-HIT Antibodies in Patients A and B}

OD values of patients $\mathrm{A}$ and $\mathrm{B}$ showed 0.51 and 0.55 , respectively, and these values were greater than 0.40 . Furthermore, these values were greater than the mean values in the patient controls $(0.13 \pm 0.02)$. When heparin was added to plasmas of patients $\mathrm{A}$ and $\mathrm{B}$, the absorbencies of these samples were decreased to approximately $50 \%$.

\subsection{Plasma Levels of TNF-Alpha, TNF-RI, and TAT}

Table 1. Plasma levels of TNF-alpha, TNF-RI, and TAT in patient $A$ and B and patient controls.

\begin{tabular}{llll}
\hline Object & TNF- $\boldsymbol{\alpha}(\mathbf{n g} / \mathbf{m L})$ & TNF-RI $(\mathbf{p g} / \mathbf{m L})$ & TAT $(\mathbf{n g} / \mathbf{m L})$ \\
\hline Patient A & 13.8 & 1853 & 12.4 \\
Patient B & 8.9 & 1728 & 11.8 \\
$\begin{array}{l}\text { Patient controls } \\
(\mathrm{n}=17)\end{array}$ & $2.2 \pm 0.1$ & $1532 \pm 362$ & $5.1 \pm 2.5$ \\
\hline
\end{tabular}

As shown in Table 1, plasma levels of TNF-alpha and TAT in patients A and B were markedly higher than the mean levels in the patient controls. Plasma levels of TNF-R1 in patients $\mathrm{A}$ and $\mathrm{B}$ were similar to the mean levels in the patient controls. 


\section{Discussion}

Heparin-induced thrombocytopenia is an immune-mediated thrombocytopenia related to an increased risk of thrombosis in patients receiving heparin treatment [42]. Efficient diagnosis of HIT requires fulfilling the clinical criteria and detection of anti-HIT antibodies. The clinical criteria for HIT include a decrease in platelet count occurring 5 to 10 days after the initiation of heparin therapy in the absence of other predominant etiological factors of thrombocytopenia, with or without thrombosis $[27,43]$. Warkentin et al. [44] reported that many HIT patients develop thrombotic complications after receiving heparin as an antithrombotic prophylaxis and the thrombotic events were observed in approximately $20 \%$ of cases. The most common thrombotic complication is venous thromboembolism [i.e., deep-vein thrombosis and pulmonary embolism], especially in postoperative patients [45]. Therefore, rapid diagnosis of HIT is necessary to avoid these events.

The IgG fraction of HIT patients serum has been found to cause in vitro platelet aggregation in the presence of therapeutic amounts of heparin [46], indicating that HIT has an immunologic etiology $[47,48]$. Several studies have found that the pro-aggregating effect of heparin depends on the degree of sulphation and the molecular weight of the heparin $[18,49,50]$ and is mediated by the release of platelet alpha-granules [51], which contain PF4, a small, positively charged molecule produced by megakaryocytes. Although its biological function is unknown, it has been identified as the main co-factor of heparin [17,52]; it also binds to endothelial-surface glycosaminoglycans, e.g., heparan sulfate $[53,54]$. Normal blood levels of PF4 are very low, as it is only released into circulation following weak platelet activation. When heparin binds with PF4, it undergoes a conformational change and becomes immunogenic, leading to the generation of anti-heparin/PF4 antibodies, namely, HIT antibodies [55,56]. The PF4/heparin ratio is important for the constitution of the multimolecular antigenic complex, and the optimal PF4/heparin ratio has been reported to range from 4-6:1 [18,53,57]. The immunogenicity of heparin-PF4 conjugates may form the biological basis for differences in immunogenicity between bovine and porcine sources of heparin: Bovine lung heparin has longer polysaccharide chains and a higher degree of sulphation, which could increase reactivity with PF4 [58].

We measured ant-HIT antibody of eight HIT suspected patients who underwent CABG $(\mathrm{n}=4), \operatorname{PTCA}(\mathrm{n}=2)$, and prosthetic mitral valve replacement $(n=2)$ before in two years. The number of the platelets of these patients was a low value than $\geq 50 \%$ or $150 \times 10^{9} / \mathrm{L}$ after a start heparin therapy in the $14^{\text {th }}$ day. However, we were not able to judge these patients to be HIT-positive because we were not able to detect ant-HIT antibody in the blood of these patients. In the present study, we investigated 2 patients (patients A and B) in whom thrombocytopenia, which was induced after initiation of UFH administration during PTCA or CABG surgery, disappeared after the cessation of UFH. These patients had been suspected of having HIT because of a striking decrease in platelet counts [i.e., less than $100 \times$ $10^{9} / \mathrm{L}$ ] occurring within 5 days of UFH administration as an anticoagulant therapy during PTCA or CABG surgery and recovery to the normal range following cessation of UFH. HIT is clinically defined as an acquired platelet count of lower than $100 \times 10^{9} / \mathrm{L}$ or a $50 \%$ decrease from baseline values, occurring 5 to 10 days after the initiation of UFH therapy in the absence of other etiological factors $[59,60]$.

The platelet aggregation test is able to provide quicker results [61], although the results vary considerably more than those reported for ${ }^{14} \mathrm{C}$-serotonin release assay (SRA) in relation to the different heparin concentrations, and donor platelet variability $[9,11,62]$. The platelet activation tests are based on the detection of donor platelet activation in the presence of the patient's plasma or serum and heparin. Platelet aggregation performed with citrated platelet-rich plasma, is commonly used to detect platelet-activating HIT antibodies. However, to increase its sensitivity and specificity, test conditions need to be optimized including using washed platelets $[7,19,63]$. In Japan, several kinds of platelet aggregometer are used to detect platelet activation or aggregation in several university hospitals and large hospitals. However, this method is technically demanding and time-consuming. To avoid these problems, laboratory testing for diagnosis of HIT will be required human resource development and improvement of methodological guidelines. Recently, Multiplate ${ }^{\circledR}$ analyzer (Dynabyte, Munich, Germany), which is a semi-automated and easy-to -perform platelet aggregation assay, is developed. This analyzer may bring to development of determination of platelet aggregatory. Furthermore, automated-analyzer induces simple and easy procedure of anti-HIT antibodies, TNF-alpha and TAT. Therefore, these methods may bring more rapid diagnose HIT in real-world clinical practice.

To detect HIT antibodies, we measured platelet aggregation using platelet-rich plasma assay. When PRP samples obtained from Healthy volunteers were stimulated with ADP $5.0 \mu \mathrm{M}$, secondary aggregation was induced. This aggregation is irreversible, and is associated with the synthesis of thromboxane $A_{2}$ and secretion from platelets of various substances such as ADP, PF-4, and P-selectin [36,64-66]. These PRP samples in response to $1.0 \mu \mathrm{g} / \mathrm{mL}$ of collagen also were induced strong aggregation. This aggregation caused various reactions such as the release of various substances from platelets [36,37]. On the other hand, PRP samples obtained from Healthy volunteers in response to ADP $1.0 \mu \mathrm{M}$ as well as collagen $0.2 \mu \mathrm{g} / \mathrm{mL}$ were induced weak aggregation. When PRP aggregation control samples (incubation without UFH) of patients A and B were stimulated with the same agonists, weak aggregation was induced as well as PRP samples obtained from Healthy volunteers. However, platelet aggregation of two patients was strikingly enhanced after the addition of UFH, suggesting the existence of heparin-related antibodies in their plasma. From these results, we consider that this 
method is useful to detect HIT antibody. Furthermore, we performed platelet aggregation test according to procedure of HIT information center [40], and this method is a wide use in Japan. When the plasma sample from each of the patients was added, along with UFH, to the PRP sample from a healthy volunteer, platelet aggregation was markedly enhanced in response to $0.2 \mu \mathrm{g} / \mathrm{mL}$ of collagen. These results suggest that the heparin-related antibodies from the 2 patients who received UFH induced platelet aggregation through binding to activated platelets.

In addition, we analyzed the levels of anti-HIT antibodies by using commercial ELISA kits and obtained positive OD values for both patients. The official cut-off for a positive result is set at about 0.4 for the GTI PF4 Enhanced ELISA. However, several groups have shown a more clinically relevant cut-off. Regarding the threshold to judge intermediate or high pretest probability of HIT, Lo et al. [67] set up more than 1.20 OD units, Warkentin et al. [68] set up more than 1.40 OD units, and Nellen et al. [69] set up more than 1.367 OD units. However, these OD values are exactly three times the manufacturer's recommended cut-off. On the other hand, Schenk et al. [70] reported that a higher EIA GTI cutoff $(\mathrm{OD} \geq 1.0)$ led to a considerable loss of diagnostic sensitivity and to the risk of not identifying $20 \%$ of the platelet-activating, presumably clinically relevant, antibodies. Our decision related with HIT positive OD values is based on this report. OD values of patients $A$ and $B$ were greater than 0.40 . Furthermore, these values were greater than the mean values in the patient controls. When heparin was added to plasmas of patients $\mathrm{A}$ and $\mathrm{B}$, the absorbencies of these samples were decreased to approximately $50 \%$. HIT positive was established by this phenomenon. If patients' plasma samples were negative in the platelet aggregation test but positive in the anti-HIT antibodies, these plasma contained the anti-HIT antibodies only of the IgM or IgA class, which are not able to be detected by the HIT ELISA kit, whereas the platelet aggregation test detect only IgG HIT antibodies, as they are caused by FcRII-dependent platelet activation [18,61]. Wakentin et al. [71] reported that additional detection of $\operatorname{IgA}$ and IgM antibodies by the GTI ELISA kit worsened test specificity by detecting non-pathogenic antibodies. Therefore, we consider that an EIA that detects anti-HIT antibodies of only the IgG class has greater diagnosis usefulness in revealing clinical HIT than an assay that also detects IgM and IgA class antibodies. We concluded that the 2 patients were positive for HIT, based not only on our laboratory data but also on clinical observations such as the decrease in platelet counts within 5 days of UFH administration.

The strong platelet aggregation induced in response to a weak agonist, such as $1 \mu \mathrm{M}$ of ADP and $0.2 \mu \mathrm{g} / \mathrm{mL}$ of collagen, may be explained by the finding that anti-HIT antibodies bind to heparin-PF4 complexes expressed on the surface of platelets and monocytes via the Fc $\gamma$ RIIA receptors. This results in the strong induction of platelet activation and degranulation, which are characterized by the release of procoagulant substances such as serotonin, histamine, and ADP in thromboxane biosynthesis in $\mathrm{Ca}^{2+}$ influx; and in the generation of highly prothrombotic phospholipids microparticles [20,22]. Several reports demonstrated that activation of platelets, monocytes and other vascular cells caused by anti-HIT antibodies would contribute not only to the developing thrombocytopenia but also to the production of tissue factor by monocytes, and these phenomena could contribute to the inflammatory state and the thrombotic complications in HIT patients [24,25].

In the present study, we observed remarkably high levels of TNF-alpha and TAT in the suspected HIT patients. These values were markedly higher than the mean levels in the patient controls (patients who underwent $\mathrm{CABG}$ without thrombocytopenia after heparin therapy initiation). The high values of TNF-alpha in our data might support a report indicating that anti-HIT antibodies bind to endothelial cells and directly activate microvascular endothelial cells, and that these phenomena might require pre-activation by platelets or TNF-alpha [72]. High levels of TAT in suspected HIT patients indicated that blood coagulation was markedly accelerated, which might lead to increased risk of thrombosis. Our consideration is supported by the report that many HIT patients are a hypercoagulable state accompanied with the greatly elevated levels of TAT [73,74]. Furthermore, this helps explain the strong relationship between HIT and venous or arterial thrombosis [22]. Rapid diagnosis of HIT is necessary to avoid thrombotic event. In the present study, we detected HIT positive patients by platelet aggregability and HIT ELISA kit. While washed platelet methods is a useful assay for heparin-dependent platelet activating antibodies, handling of this methods is very complicated and is sometimes induced platelet activation. On the other hand, our method based on the procedure of HIT information center in Japan is very easy to make clear HIT positive patients, and possess high reproducibility of the data. We could diagnose the two patients as being positive for HIT among patients who received UFH during PTCA or post-CABG surgery. These data support the idea that our study provides the beneficial information to detect HIT positive patients. However, two HIT positive patients are small for discussion of relationship between anti-HIT antibodies and hypercoagulability and between anti-HIT antibodies and inflammatory markers (TNF- $\alpha$ and interleukin 8). Therefore, we consider that an increase in the number of the detection of the HIT-positive patients is necessary to make these relationships clear.

In conclusion, the measurement of platelet aggregation and detection of anti-HIT antibodies are important for accurate HIT diagnosis. Measurement of both levels of TNF-alpha and TAT may be useful in anticoagulant therapy for preventing thrombosis formation.

\section{Acknowledgements}

We wish to thank the doctors at Department of Cardiovascular Surgery, Kagoshima University, Graduate School of Medical: Dr Takayuki Ueno, Dr Goichi 
Yotsumoto. We also thank the doctor at Sinkyo Hospital: Kenichi Miyahara. We thank Professor Ikurou Maruyama for the data detailed statistical advice at Donated department of Cardiac Repair and Regeneration, Graduate School of Medical and Dental Sciences, Kagoshima University. We thank the staff each hospital for helping with patient enrollment and data collection.

\section{References}

[1] B. Girolami, P. Prandoni, P.M. Stefani, C. Tanduo, P. Sabbion, P. Eichler, R. Ramon, G. Baggio, F. Fabris, A. Girolami. The incidence of heparin-induced thrombocytopenia in hospitalized medical patients treated with subcutaneous unfractionated heparin: a prospective cohort study. Blood, vol. 8, pp. 2955-2959, Apr 2003.

[2] J. Hirsh, N. Heddle, J.G. Kelton. Treatment of heparin-induced thrombocytopenia: a critical review. Arch Intern Med, vol. 8, pp. 361-369, Feb 2004.

[3] E. Shantsila, G.Y. Lip, B.H. Chong. Heparin-induced thrombocytopenia. A contemporary clinical approach to diagnosis and management. Chest, vol. 6, pp. 1651-1664, Jun 2009 .

[4] S. Battistelli, A. Genovese, T. Gori. Heparin-induced thrombocytopenia in surgical patients. Am J Surg, vol. 1, pp. 43-51, Jan 2010.

[5] M. J. Zibaeenezhad, Y. Mazloum. Heparin infusion after successful percutaneous coronary intervention: a prospective randomized trial. Acta Cardiol, vol. 1, pp. 65-70, Feb 2009.

[6] G. Montalescot, V Polle, J.P. Collet, P. Leprince, A. Bellanger, I. Gandjbakhch, D. Thomas. Low molecular weight heparin after mechanical heart valve replacement. Circulation, vol. 10, pp. 1083-1086, Mar 2000.

[7] B.H. Chong, J. Burgess, F. Ismail. The clinical usefulness of the platelet aggregation test for the diagnosis of heparin-induced thrombocytopenia. Thromb Haemost, vol. 4, pp. 344-350, Apr 1993.

[8] P. Fondu. Heparin-associated thrombocytopenia: an update. Acta Clin Belgica, vol. 6, pp. 343-357, 1995.

[9] B.H. Chong. Heparin-induced thrombocytopenia. Br J Haematol, vol. 3, pp. 431-439, Mar 1995.

[10] T.E. Warkentin, M.N. Levine, J. Hirsh, P. Horsewood, R.S Roberts, M. Gent, J.G. Kelton. Heparin-induced thrombocytopenia in patients treated with low-molecular-weight heparin or unfractionated heparin. $\mathrm{N}$ Engl J Med, vol. 20, pp. 1330-1335, May 1995.

[11] B.H. Chong. Heparin-induced thrombocytopenia. Aust N Z J Med, vol. 2, pp. 145-152, Apr 1992.

[12] T.E. Warkentin, J.G. Kelton. A 14-year study of heparin-induced thrombocytopenia. Am J Med, vol. 5, pp. 502-507, Nov 1996.

[13] F. Fabris, G. Luzzatto, P.M. Stefani, B. Girolami, G. Cella, A. Girolami. Heparin-induced thrombocytopenia. Heparin-induced thrombocytopenia. Haematologica, vol. 1, pp. 72-81, Jan 2000.
[14] D.E. Wallis, D.L. Workman, B.E. Lewis, L. Steen, R. Pifarre, J.F. Moran. Failure of early heparin cessation as treatment for heparin-induced thrombocytopenia. Am J Med, vol. 6, pp. 629-635, Jun 1999.

[15] J.G. Kelton. Heparin-induced thrombocytopenia: an overview. Blood Rev, vol. 1, pp. 77-80, Mar 2002.

[16] T.P. Baglin. Heparin induced thrombocytopenia thrombosis (HIT/T) syndrome: diagnosis and treatment. J Clin Pathol, vol. 4, pp. 272-274, Apr 2001.

[17] J. Amiral, F. Bridey, M. Dreyfus, A.M. Vissoc, E. Fressinaud, M. Wolf, D. Meyer. Platelet factor 4 complexed to heparin is the target for antibodies generated in heparin-induced thrombocytopenia. Thromb Haemost, vol. 1, pp. 95-96, Jul 1992.

[18] J.G. Kelton, J.W. Smith, T.E. Warkentin, C.P. Hayward, G.A. Denomme, P. Horsewood. Immunoglobulin G from patients with heparin-induced thrombocytopenia binds to a complex of heparin and platelet factor 4. Blood, vol. 11, pp. 3232-3239, Jun 1994.

[19] A. Greinacher, B. Pötzsch, J. Amiral, V. Dummel, A. Eichner, C. Mueller-Eckhardt. Heparin-associated thrombocytopenia: isolation of the antibody and characterization of a multimolecular PF4-heparin complex as the major antigen. Thromb Haemost, vol. 2, pp. 247-251, Feb 1994.

[20] B.H. Chong, C.S. Grace, M.C. Rozenberg. Heparin-induced thrombocytopenia: effect of heparin platelet antibody on platelets. Br J Haematol, vol. 4, pp. 531-540, Dec 1981.

[21] B.H. Chong, I. Fawaz, C.N. Chesterman, M.C. Berndt. Heparin-induced thrombocytopenia: mechanism of interaction of the heparin-dependent antibody with platelets. Br J Haematol, vol. 2, pp. 235-240, Oct 1989.

[22] T.E. Warkentin, J.G. Kelton. Temporal aspects of heparin-induced thrombocytopenia. N Engl J Med, vol. 17, pp. 1286-1292, Apr 2001.

[23] T.E. Warkentin, J.I. Sheppard. Generation of platelet-derived microparticles and procoagulation activity by heparin-induced thrombocytopenia IgG/serum and other IgG platelet agonists: a comparison with standard platelet agonists. Platelets, vol. 5, pp. 319-326, 1999.

[24] G.M. Arepally, I.M. Mayer. Antibodies from patients with heparin-induced thrombocytopenia stimulate monocytic cells to express tissue factor and secrete interleukin-8. Blood, vol. 4, pp. 1252-1254, Aug 2001.

[25] C. Pouplard, S. Iochmann, B. Renard, O. Herault, P. Colombat, J. Amiral, Y. Gruel. Induction of monocyte tissue factor expression by antibodies to heparin-platelet factor 4 complexes developed in heparin-induced thrombocytopenia. Blood, vol. 10, pp. 3300-3302, May 2001.

[26] Lee D.H, Warkentin T.E. Frequency of heparin-induced thrombocytopenia. In: Warkentin T.E, Greinacher A editors. Heparin-induced thrombocytopenia, 3rd ed. NY: Marcel Dekker press, 2004, pp. 107-48.

[27] T.E. Warkentin, A. Greinacher. Heparin-induced thrombocytopenia: recognition, treatment, and prevention. The seventh ACCP Conference on Antithrombotic and Thrombolytic Therapy. Chest, 3 Suppl, pp. 311S-337S, Sep 2004. 
[28] N. Martel, J. Lee, P.S. Wells. Risk for heparin-induced thrombocytopenia with unfractionated and low-molecular-weight heparin thromboprophylaxis: a meta-analysis. Blood, vol. 8, pp. 2710-2715, Oct 2005.

[29] J.L. Francis, G.J. 3rd. Palmer, R. Moroose, A. Drexler Comparison of bovine and porcine heparin in heparin antibody formation after cardiac surgery. Ann Thorac Surg, vol. 1, pp. 17-22, Jan 2003.

[30] T.E. Warkentin. Clinical picture of heparin-induced thrombocytopenia. In: T.E. Warkentin, A. Greinacher editors Heparin-induced thrombocytopenia. 3rd ed. NY: Marcel Dekker press, 2004, pp. 53-106.

[31] T.E. Warkentin, N.M. Heddle. Laboratory diagnosis of immune heparin-induced thrombocytopenia. Curr Hematol Rep, vol. 2, pp. 148-157, Mar 2003.

[32] A. Lillo-Le Louët, P. Boutouyrie, M. Alhenc-Gelas, C. Le Beller, I. Gautier, M. Aiach , D. Lasne. Diagnostic score for heparin-induced thrombocytopenia after cardiopulmonary bypass. J Thromb Haemost, vol. 11, pp. 1882-1888, Nov 2004.

[33] Y. Gruel, S. Régina, C. Pouplard. Usefulness of pretest clinical score (4Ts) combined with immunoassay for the diagnosis of heparin-induced thrombocytopenia. Curr Opin Pulm Med, vol. 5, pp. 397-402, Sep 2008.

[34] B. Denys, V. Stove, J. Philippé, K. Devreese. A clinical-laboratory approach contributing to a rapid and reliable diagnosis of heparin-induced thrombocytopenia. Thromb Res, vol. 1, pp. 137-145, 2008.

[35] K. Nakamura. Heparin-induced thrombocytopenia. In: Charles H. Lawrie, ed. Hematology- Science and Practice. Croatia: In Tech, 2012, pp 517-540.

[36] H. Toyohira, K. Nakamura, H. Kariyazono, K. Yamada, Y. Moriyama, S. Shimokawa, H. Saigenji, A. Taira. Significance of combined use of anticoagulants and antiplatelet agents in the early stage after prosthetic valve replacement. Kyobu Geka, vol. 9, pp. 749-55, Aug 1995.

[37] H. Kariyazono, K. Nakamura, T. Shinkawa, Y. Moriyama, H. Toyohira, A. Taira, K. Yamada. Inhibitory effects of antibiotics on platelet aggregation in vitro. Hum Exp Toxicol, vol 11, pp. 662-666, Nov 1997.

[38] K. Nakamura, H. Kariyazono, M. Masuda, R. Sakata, Y. Yamada. Effects of sarpogrelate hydrochloride onadenosine diphosphate- or collagen-induced platelet response in arteriosclerosis obliterans. Blood Coagul Fibrinolysis, vol. 5, pp. 391-397, Jul 2001.

[39] A. Greinacher, J. Amiral, V. Dummel, A. Vissac, V. C. Mueller-Eckhardt. Laboratory diagnosis of heparin-associated thrombocytopenia and comparison of platelet aggregation test, heparin-induced platelet activation test, and platelet factor 4/heparin enzyme-linked immunosorbent assay. Transfusion, vol. 5, pp. 381-385, May 1994.

[40] Y. Ozaki, T. Matuo, S. Okamoto, Y. Ikeda. Heparin-induced thrombocytopenia, HIT information center Press, Japan, 2004, pp. 1-22.

[41] N.L. Whitlatch, S.L. Perry, T.L. Ortel. Anti-heparin/platelet factor 4 antibody optical density values and the confirmatory procedure in the diagnosis of heparin-induced thrombocytopenia. Thromb Haemost, vol. 4, pp. 678-684, Oct 2008

[42] T.E. Warkentin. Heparin-induced thrombocytopenia: a clinicopathologic syndrome. Thromb Haemost, vol. 2, pp. 439-447, Aug 1999.

[43] G.K. Lo, D. Juhl, T.E. Warkentin, C.S. Sigouin, P. Eichler, A. Greinacher. Evaluation of pretest clinical score (4 T's) for the diagnosis of heparin-induced thrombocytopenia in two clinical settings. J Thromb Haemost, vol. 4, pp. 759-765, Apr 2006.

[44] T.E. Warkentin. Heparin-induced thrombocytopenia: IgG-mediated platelet activation, platelet microparticle generation, and altered procoagulant/anticoagulant balance in the pathogenesis of thrombosis and venous limb gangrene complicating heparin-induced thrombocytopenia. Transfus Med Rev, vol. 4, pp. 249-258, Oct 1996.

[45] A.P. Betrosian, G. Theodossiades, G. Lambroulis, D. Kostantonis, M. Balla, M. Papanikolaou, G. Georgiades. Heparin-induced thrombocytopenia with pulmonary embolism and disseminated intravascular coagulation associated with low-molecular-weight heparin. Am J Med Sci, vol. 1, pp. 45-47, Jan 2003.

[46] K. Althaus, G. Hron, U. Strobel, R. Abbate, A. Rogolino, S. Davidson, A. Greinacher, T. Bakchoul. Evaluation of automated immunoassays in the diagnosis of heparin induced thrombocytopenia. Thromb Res, vol. 3, pp. 85-90, Mar 2013.

[47] J. Amiral, A. Marfaing-Koka, M. Poncz, D. Meyer. The biological basis of immune heparin-induced thrombocytopenia. Platelets, vol. 2, pp. 77-91, 1998.

[48] T.E. Warkentin, J.A. Sheppard, P. Horsewood, P.J. Simpson, J.C. Moore, J.G. Kelton. Impact of the patient population on the risk for heparin-induced thrombocytopenia. Blood, vol. 5 , pp. 1703-1708, Sep 2000.

[49] A. Greinacher, I. Michels, C. Mueller-Eckhardt. Heparin-associated thrombocytopenia: the antibody is not heparin specific. Thromb Haemost, vol. 5, pp. 545-549, May 1992.

[50] A. Greinacher, I. Michels, U. Liebenhoff, P. Presek, C. Mueller-Eckhardt. Heparin-associated thrombocytopenia: immune complexes are attached to the platelet membrane by the negative charge of highly sulphated oligosaccharides. $\mathrm{Br}$ J Haematol, vol. 4, pp. 711-716, Aug 1993.

[51] Y. Gruel, B. Boizard-Boval, J.L. Wautier. Further evidence that alpha-granule components such as platelet factor 4 are involved in platelet-IgG-heparin interactions during heparin-associated thrombocytopenia. Thromb Haemost, vol. 2, pp. 374-375, Aug 1993.

[52] G. Gentilini, N.E. Kirschbaum, J.A. Augustine, R.H. AsterH, G.P. Visentin. Inhibition of human umbilical vein endothelial cell proliferation by the CXC chemokine, platelet factor 4 (PF4), is associated with impaired downregulation of p21(Cip1/WAF1). Blood, vol. 1, pp 25-33, Jan 1999.

[53] G.P. Visentin, S.E. Ford, J.P. Scott, R.H. Aster. Antibodies from patients with heparin-induced thrombocytopenia/thrombosis are specific for platelet factor 4 complexed with heparin or bound to endothelial cells. Clin Invest, vol. 1, pp. 81-88, Jan 1994. 
[54] S. Pillarisetti, L. Paka, A. Sasaki, T. Vanni-Reyes, B. Yin, N. Parthasarathy, W.D. Wagner, I.J. Goldberg. Endothelial cell heparanase modulation of lipoprotein lipase activity. Evidence that heparan sulfate oligosaccharide is an extracellular chaperone. J Biol Chem, vol. 25, pp. 15753-15759, Jun 1997.

[55] J.S. Suh, R.H. Aster, G.P. Visentin. Antibodies from patients with heparin-induced thrombocytopenia/thrombosis recognize different epitopes on heparin: platelet factor 4. Blood, vol. 3, pp. 916-922, Feb 1998.

[56] L. Ziporen, Z.Q. Li, K.S. Park, P. Sabnekar, W.Y. Liu, G. Arepally, Y. Shoenfeld, T. Kieber-Emmons, D.B. Cines, M. Poncz. Defining an antigenic epitope on platelet factor 4 associated with heparin-induced thrombocytopenia. Blood, vol. 9, pp 3250-3259, Nov 1998.

[57] J. Amiral, F. Bridey, M. Wolf, C. Boyer-Neumann, E. Fressinaud, A.M. Vissac, E. Peynaud-Debayle, M. Dreyfus, D. Meyer. Antibodies to macromolecular platelet factor 4-heparin complexes in heparin-induced thrombocytopenia: a study of 44 cases. Thromb Haemost, vol. 1, pp. 21-28, Jan 1995.

[58] L.K. Boshkov, T.E. Warkentin, C.P. Hayward, M. Andrew, J.G. Kelton. Heparin-induced thrombocytopenia and thrombosis: clinical and laboratory studies. Br J Haematol, vol. 2, pp. 322-328, Jun 1993.

[59] T.E. Warkentin. Platelet count monitoring and laboratory testing for heparin-induced thrombocytopenia. Arch Pathol Lab Med, vol. 11, pp. 1415-1423, Nov 2002.

[60] R.A. Saad. Heparin-induced thrombocytopenia: pathogenesis and management. Br J Haematol, vol. 2, pp. 373-374, Oct 2003.

[61] J.G. Kelton, D. Sheridan, A. Santos, J. Smith, K. Steeves, C. Smith, C. Brown, W.G. Murphy. Heparin-induced thrombocytopenia: laboratory studies. Blood, vol. 3, pp. 925-930, Sep 1988.

[62] C. Bachelot-Loza, R. Saffroy, D. Lasne, G. Chatellier, M. Aiach, F. Rendu. Importance of the FcgammaRIIa-Arg/His-131 polymorphism in heparin-induced thrombocytopenia diagnosis. Thromb Haemost, vol. 3, pp. 523-528, Mar 1998.

[63] C. Pouplard, M.A. May, S. Iochmann, J. Amiral, A.M. Vissac, M. Marchand, Y. Gruel. Antibodies to platelet factor 4-heparin after cardiopulmonary bypass in patients anticoagulated with unfractionated heparin or a low-molecular-weight heparin: clinical implications for heparin-induced thrombocytopenia. Circulation, vol. 19, pp. 2530-2536, May 1999.

[64] M.A. Orchard, K.A. Waddell, P.J. Lewis, I.A. Blair IA. Thromboxane synthase inhibition causes re-direction of prostaglandin endoperoxides to prostaglandin D2 during collagen stimulated aggregation of human platelet rich plasma. Thromb Res, vol. 6, pp. 701-710, Sep 1985.

[65] B.W. Böttiger, H. Böhrer, T. Böker, J. Motsch, M. Aulmann, E. Martin. Platelet factor 4 release in patients undergoing cardiopulmonary resuscitation--can reperfusion be impaired by platelet activation? Acta Anaesthesiol Scand, vol. 5, pp. 631-635, May 1996.

[66] J.N. Zhang, A.L. Bergeron, Q. Yu, C. Sun, L. McBride, P.F. Bray, J.F. Dong. Duration of exposure to high fluid shear stress is critical in shear-induced platelet activation-aggregation. Thromb Haemost, vol. 4, pp. 672-678, Oct 2003.

[67] G.K. Lo, C.S. Sigouin, T.E. Warkentin. What is the potential for overdiagnosis of heparin-induced thrombocytopenia? Am J Hematol, vol. 12, pp. 1037-1043, Dec 2007.

[68] T.E. Warkentin, J.I. Sheppard, J.C. Moore, C.S. Sigouin, J.G. Kelton. Quantitative interpretation of optical density measurements using PF4-dependent enzyme-immunoassays. J Thromb Haemost, vol. 8, pp. 1304-1312, Aug 2008.

[69] V. Nellen, I. Sulzer, G. Barizzi, B. Lämmle, L. Alberio. Rapid exclusion or confirmation of heparin-induced thrombocytopenia: a single-center experience with 1,291 patients. Haematologica, vol. 1, pp. 89-97, Jan 2012.

[70] S. Schenk, A. El-Banayosy, M. Morshuis, L. Arusoglu, P. Eichler, N. Lubenow, G. Tenderich, R. Koerfer, A. Greinacher, W. Prohaska. IgG classification of anti-PF4/heparin antibodies to identify patients with heparin-induced thrombocytopenia during mechanical circulatory support. J Thromb Haemost, vol. 2, pp. 235-241, Feb 2007.

[71] T.E. Warkentin, J.A. Sheppard, J.C. Moore, K.M. Moore, C.S. Sigouin, J.G. Kelton. Laboratory testing for the antibodies that cause heparin-induced thrombocytopenia: how much class do we need? J Lab Clin Med, vol. 6, pp. 341-346, Dec 2005.

[72] J.M. Walenga, W.P. Jeske, M.M. Prechel, M. Bakhos. Newer insights on the mechanism of heparin-induced thrombocytopenia. Semin Thromb Hemost, vol. Suppl 1, pp. 57-67, Feb 2004.

[73] T.E. Warkentin , L.J. Elavathil, C.P. Hayward, M.A. Johnston, J.I. Russett, J.G. Kelton. The pathogenesis of venous limb gangrene associated with heparin-induced thrombocytopenia. Ann Intern Med, vol. 9, pp. 804-812, Nov 1997.

[74] L. Chilver-Stainer, B. Lämmle, L. Alberio. Titre of anti-heparin/PF4-antibodies and extent of in vivo activation of the coagulation and fibrinolytic systems. Thromb Haemost, vol. 2, pp. 276-282, Feb 2004. 